\author{
Research Article
}

\title{
Effects of Open-Top Chamber on Soil Chemical Properties and Microbial Growth
}

\author{
Cheah Yoke Kqueen ${ }^{1 *}$, Maryam Abdulla Seif ${ }^{1}$, Mohamed Ikhtifar Rafi ${ }^{1}$, Lim Wei Meng ${ }^{1}$, Clemente \\ Michael Wong Vui Ling ${ }^{2}$ and Geok Yuan Annie Tan ${ }^{3}$ \\ ${ }^{1}$ Department of Biomedical Science, Faculty of Medicine and Health Sciences, Universiti Putra Malaysia, 43400 Serdang, Selangor Darul Ehsan, Malaysia \\ 2 Biotechnology Research Institute, Universiti Malaysia Sabah, Jalan UMS, Kota Kinabalu, Sabah, Malaysia \\ ${ }^{3}$ Institute of Biological Sciences, Faculty of Science, University of Malaya, Kuala Lumpur, Malaysia
}

https://doi.org/10.28916/lsmb.2.3.2018.18

Received 3 July 2018, Revisions received 24 November 2018, Accepted 24 November 2018, Available online 25 December 2018

\begin{abstract}
Global warming is the main concern in today's century as it comes with numerous side effects to the natural environment. Open Top Chambers (OTC) consist of metal constructions with transparent vertical side-walls and a frustum on top. An opening in the middle of the frustum allows an air exchange to reduce temperature and humidity effects in the chamber. The size of the open top chamber which is located in Universiti Putra Malaysia is slanted $60^{\circ}, 50 \mathrm{~cm}$ tall, $2.08 \mathrm{~m}$ basal diameter hexagon chamber. The Open Top Chamber experiments were carried out to determine how much global warming has affected and is still affecting the temperature, $\mathrm{pH}$, the moisture and the growth of the microbes in the tropical soil. The aim of this study is to elucidate the effects of temperature increase on the soil microbes' population and on the $\mathrm{pH}$ of the soil. The study was conducted to observe the effect of heat on the population of soil microbes and the $\mathrm{pH}$ of the soil which was collected on the same day for 6 consecutive months. The microbes from the samples were grown on agar plates. The population of microbes on the plates were used as values were for Colony Forming Unit (CFU) value calculations. The effects of OTCs on mean temperature showed a large range of CFU values throughout the 6 months but did not differ significantly between studies. Increases in mean monthly and diurnal temperature were strongly related, indicating that the presence of warming effect by the OTCs. Such predictive power allows a better mechanistic understanding of observed biotic response to experimental warming. This study will be useful for the understanding of the global warming effect on microbes. The Open Top Chamber experiment has proven to be one of the effective model for global warming research and data collected especially on the growth of soil microbial obtained would be of great use for further experiments.
\end{abstract}

Keywords: Open top chamber, global warming, soil chemical properties, microbial growth

\section{Introduction}

Generally, global warming refer as a gradual increase in the average temperature of the Earth's atmosphere as well as the oceans and this change is actually believed to be influencing the Earth's climate and as such the planet is getting warmer as the days go by. Although global warming is alarming, not many people study the effects of global warming as substantial and more rapidly occurring. Based on the studies on global warming, it was reported that the average temperature of the Earth has been observed to rise by about $0.8^{\circ} \mathrm{C}$ since the beginning of the 19th century (Michael J.et al, June 21, 2012).

Studies have shown that global warming is the result of the increased in carbon dioxide level and the primary reasons of global warming have been attributed to human activities such as burning of fossil fuels, agriculture and land clearing using fire that have been going on for years (James J. Hoorman, 2017). Through extensive research, scientists have predicted that the average temperature for global warming could increase in the range of 1.4 to 5.8 degrees by 2100 . However if the temperature increases as predicted, it is expected to increase the rates of organic matter decomposition by soil microorganisms which are very important part of the soil particles. These soil microorganisms are also one of the important sources of knowledge about the strategies and limits of life. Microorganisms are best known to be of critical importance to the sustainability of life on our planet and play a vital role in maintaining ecological balance within the environment. The increase of soil acidity may affect micro-organisms which break down organic matter into nutrient that can be used by plants or other organism. The microorganisms exist in very large numbers in the soil as long as there's enough nutrients and suitable condition. Moreover, studies have indicated that the amount of bacterial is higher in soil because the bacterial size shows low biomass. (James J. Hoorman, 2017).

The chambers that are usually applied in the field for studying the effects of a warming ecosystem includes greenhouse-field style, tent and Open Top Chambers (OTCs) of various shapes and sizes. The use of this heating technique developed from experiments which are not concerned with increasing the temperature of the ecosystem. Various studies using OTC has been widely used in the 1980s and 1990s in

\footnotetext{
* Correspondence: Department of Biomedical Science, Faculty of Medicine and Health Sciences, Universiti Putra Malaysia, 43400 Serdang, Selangor Darul Ehsan, Malaysia

e-Mail: ykcheah@upm.edu.my
}

(C) 2018 by the Author(s). Life Sciences, Medicine and Biomedicine (ISSN: 2600-7207) Published by Biome Journals. Wholly owned by Biome Scientia Sdn Bhd., previously by WWH Networks Sdn Bhd. Attribution-ShareAlike 4.0 International (CC BY-SA 4.0). This open access article is distributed based on the terms and conditions of the Creative Commons Attribution license https://creativecommons.org/licenses/by-sa/4.0/ 
association with various forms of smoking such as ozone and carbon dioxide input. In general, the chamber has been created by open-topped cylindrical frame covered in plastic, with a hose-in fan and secured to the base of the chamber to circulate the air and gas mixture contribute. The room was open to allow gas exchange with the atmosphere, and to allow rain to enter. Such as plastic sheeting that allowed short-wave radiation, but prevents infrared waves from escaping thus it becomes very difficult to control the concentration of gas at the desired level, while also reducing the increase of air temperature and has been criticized (Kennedy \& Smith, 1995). This has led to a shift towards "free-air carbon dioxide experiment" (FACE) site for more recent studies to increased CO2 (Canadell, et al, 1995). However, experimental ecosystem warming begins to run with the greenhouse frame partially open, tent and OTC products, tailored from the hall previously used for fumigation experiment (Aronson \& McNulty, 2009).

Climate warming is reducing abiotic stress, with the possibility to transform the diversity of soil microbial community, and hence they complete various processes (Pold \& De Angelis 2013; Shade et al, 2012). Several studies had shown that how an increase in temperature affects soil organic matter decomposition. Some of these studies include studies on the diversity of the microbial community by using biochemical approaches such as fatty acid analysis, phospholipids or molecular approaches such as fingerprint or sequencing the community, with some metric or biomass of microbial activity. Both approaches can provide different complementary-view-on the microbial communities (Pold \& De Angelis, 2013). The previous study had also shown that the net effects of warming on soil microbes tend to increase the microbial activity in the short term, which translates to increased soil respiration (Melillo et al., 2011; Wu, et al , 2011). Studies conducted by Zogg et al. (1997) as cited by the Pold and DeAngelis, (2013) showed that initial laboratory incubation studies revealed moderate forest land increase in activity may be accompanied by changes in microbial biomass and community composition. However, Wu et al. (2011) had observed an increase in microbial activity also examined changes in the composition of the microbial community. There is evidence that not all soil microbial communities respond to heating in which heating more likely to have a negative impact on many microbes (density) in a location that is cool, dry place (Blankinship, et al, 2011). Furthermore, in response to the rapid warming, and perhaps more quickly than changes in the structure of the community, Thus it is possible that some of the warming effect that is caused by changes in the fraction of active biomass, of the constituent peoples (Pettersson \& Bååth, 2003).

Zhang et al. (2017) had reported that increased diversity under warming and drought, which shows that the global warming may have somehow primed society to become more resilient and survive longer lasting interruption. In the second and third full year of treatment, Zhang et al. found that increased warming treatment on the site had caused the fungal and bacterial biomass to decrease as measured using PLFA analysis. The studies had reported that while there was no heating effect on the total microbial biomass, net mineral $\mathrm{N}$ decreased, yet there is a significant change in the profile of the substrate, indicating a change in the metabolic capacity of the community. Sheik et al. (2011) had reported that in the years of normal rainfall, warming increases the size of the population, but less rich and diverse society. However, under drought conditions, the reduction in heat had increased the size of population diversity, richness and evenness, without any change in the composition of society. The authors had suggested that a change in the relative abundance of species and not making the novel encourages ecosystem function under climate change.

Soil microorganisms are the key component of belowground ecosystem. Diversity, composition, and activity of microorganisms that is important for biogeochemical cycling and the main driver productivity and diversity of terrestrial ecosystems (Mangan et al., 2010; Zhao et al., 2014). Previous studies had shown that the soil microbial community structure and its associated microbial processes deliver an important function in the $\mathrm{C}$ and $\mathrm{N}$ cycling, as in the process of litter decomposition and degradation of soil organic matter (SOM) (Xu et al., 2010). For example, the ratio of fungi-to-bacteria was negatively correlated with soil mineral nitrogen content because bacteria requires more $\mathrm{N}$ per unit biomass of the fungus for assimilation (Högberg et al., 2008). Meanwhile, the soil microorganisms vary in their ability to use SOM. Therefore, changes in community structure can affect the rate of decomposition, $\mathrm{CO} 2$ emissions, and soil C pools (Xu et al., 2010). Little change in soil microbial community structure and physiology had been considered to change the $\mathrm{C}$ and $\mathrm{N}$ cycling.

Soil microbial communities and microbial processes, such as extracellular enzyme activities, are various elements that can be altered by environmental factors. The various efforts have been made to investigate the effects of warming on the composition of the soil microbial community. However, the effects are complex and it depends on the experimental approach of heating, various treatments and ecosystems (Karhu et al., 2010; Zhang, et al, 2011). Reducing the rate of relative Gram-positive (GP) bacteria to Gram-negative (GN) bacteria or fungus, or any significant changes in the composition of microbial or an enzymatic all noted below heating in different experiments reported (Zhang et al., 2011). Activities, diversity and composition of the soil microbial community also been modified by the addition of nitrogen (Fierer et al., 2011; Ramirez, et al , 2012).

There are various shapes and sizes used for passive OTC products, ranging from small four-sided board that has been used for the International Tundra Experiment (ITEX angle) to a larger hexagonal (Marion et al., 1997). The surface area compared with the interior space of directly controlling the internal volume of the air space and the ground temperature increases. The smaller the hole relative to the height of the space, the higher the temperature increase. The hole's diameter ratio to the height of the room also affects other environmental parameters (Marion et al., 1997). Field room in their most basic form is the least expensive to build and maintain. A fan can be used to both regulate and standardize the internal air temperature, or heating ecosystem can be regulated in more detail through conversion to an active area, by passing hot air through the space (Norby et al., 1997). However, this system is most often used in remote locations where electrical applications in question, and therefore run without a fan. Unlike IR-reflective curtains, which have been deployed and retracted, the upper chamber open field or greenhouse frames are not modified once in place. However, this system has some limitations. Even with a fan to circulate the air, temperature range, as well as the diversity of the temperature difference between the control and treatment room, can be very large (Marion et al., 1997). The biggest difference in temperature occurs when the absolute and relative space are exposed to full sunlight. Although not as efficiently retain heat as a curtain, the board will reduce the heat loss at night. Therefore, this system will heat the air and ground during the day and night (provided it is a sunny day), but the majority of the warming will occur during the day. In addition to the design of space, solar angle and level cloud cover will influence the amount of heating (Marion et al., 1997).

The aim of this study is to investigate if there is any specific trend of association between microbial counts with minute changes of soil temperature due to Open Top Chamber.

\subsection{Materials and methods}

\subsection{Open top chamber}

The open top chambers consist of metal constructions with transparent vertical side-walls and a frustum on top with an opening in its middle to allow air exchange to reduce temperature and humidity effects in the chamber (Macháčová K., 2009). The open top chamber used for this study, is of a hexagonal shape (Figure.1) which was located in the Universiti Putra Malaysia (258'39.88837'N, 10143'6.22083'E) 
and the panels were fixed at $60^{\circ}$ inclination, $50 \mathrm{~cm}$ tall, $1.5 \mathrm{~m}$ open top diameter and $2.08 \mathrm{~m}$ basal diameter. A total of three OTC were placed in a distance of 2 meter apart each other.

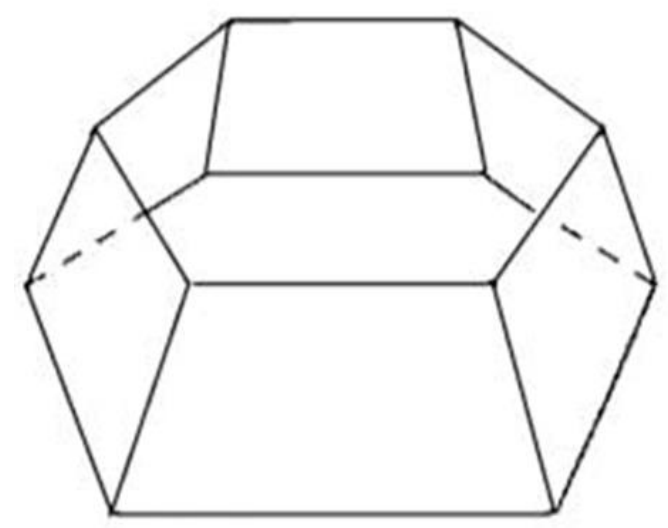

Figure 1: Hexagonal Shape Open Top Chamber. Adapted from Ulf Molau, Per Mølgaard,

(International Tundra Experiment: ITEX corners, 1996)

Approximately of $5 \mathrm{~g}$ soil was collected using sterile spatula on the same date for 6 months (November to December 2016, January to April 2017) in sterile $50 \mathrm{ml}$ falcon tubes. The soil was collected in 6 tubes; 3 for the inside and 3 for the outside of the open top chamber. The samples were processed immediately. The $\mathrm{pH}$ and the moisture of the soil were recorded each time prior to collection of the soil using a common digital $\mathrm{pH}$ and soil meter (Ketotek, China).

\section{$2.3 \quad$ Microbial culture}

A total of $9 \mathrm{ml}$ of Tryptic soy broth were poured into a $50 \mathrm{ml}$ falcon tube. $1 \mathrm{~g}$ of the collected soil was added to it and then vortexed for 10 seconds. The tubes were then incubated for 24 hours at $37^{\circ} \mathrm{C}$. Serial dilutions were applied for each of the tubes to obtain a total concentration of $1 \times 10^{11}$ and $1 \times 10^{12}$ (Selected concentration based on previous study, unpublished data). This was to ensure that the concentration of bacteria was low enough in order to count and calculate the colony forming units. Then, $100 \mathrm{ul}$ of the final concentrations were pipetted out and placed onto the Tryptic Soy Agar (BD Difco, USA). The drops were spread equally by using a sterile spreader. The steps were repeated for each of the samples and were done in triplicates.

\section{Colonies counting}

The calculation of colonies formed was done manually for each plate. In order to keep the count accurate, different colour markers were used for each section to identify how much microbes were in each plate. Continuous calculation of colonies were recorded at 6-hours, 24-hours and 48-hours.

\section{Colony-forming unit}

Colony Forming Unit formulae was applied to determine the colonies formed from the sample. For each of the plates, the values were recorded accordingly to each time point and for each serial dilution the total and the average values were calculated. Below is the formula used for the calculation for Colony Forming Unit.

$$
\mathrm{CFU}=[\text { no. of colonies } \mathrm{x} \text { dilution factor }] / \text { volume of culture plate }
$$

\section{Statistical analysis}

Statistical calculations were tabulated using IBM SPSS Statistics for Windows, Version 17.0. The statistical test applied was T-test which was calculated using the value of CFU. All the statistical analyses, a p-value of $<0.05$ (95\% confidence interval) was considered to be statistically significant.

\subsection{Results}

3.1 Soil moisture and $\mathrm{pH}$ level

The data obtained indicated that the weather has been the most contributing factor as most of the months the soil detected to be wet but for the month of December 2016, February 2017 and March 2017 the reading was dry for both locations (Table 1). The data obtained for $\mathrm{pH}$ indicate that soil inside the chamber is more acidic (range of 5.0) but in March, the reading reached up to 6.

Generally, most of the soils' condition were detected as wet throughout November 2016 to April 2018 either inside or outside the OTC. Overall, soil's pH inside the OTC range between 5 to 6 (Figure 2). OTC 2 and 3 indicated consistent profile except in March and OTC 1 showed minor fluctuation between 5 to 5.5. In contrast, soil's pH outside the OTC remains between 4 to 6 November 2016 to April 2017 among OTC 1 to OTC 3. 
Table 1: The Soil's OTC Moisture Reading for 3 Different Units

\begin{tabular}{lcccccc}
\hline \multirow{2}{*}{ Month } & \multicolumn{2}{c}{ OTC 1 } & \multicolumn{2}{c}{ OTC 2 } & \multicolumn{2}{c}{ OTC 3 } \\
\cline { 2 - 7 } & Inside & Outside & Inside & Outside & Inside & Outside \\
\hline November 2016 & Wet & Wet & Wet & Wet & Wet & Wet \\
December 2016 & Dry & Dry & Wet & Wet & Wet & Wet \\
January 2017 & Wet & Wet & Wet & Wet & Wet & Wet \\
February 2017 & Wet & Wet & Wet & Wet & Dry & Dry \\
March 2017 & Wet & Wet & Wet & Wet & Dry & Dry \\
April 2017 & Wet & Wet & Wet & Wet & Wet & Wet \\
\hline
\end{tabular}
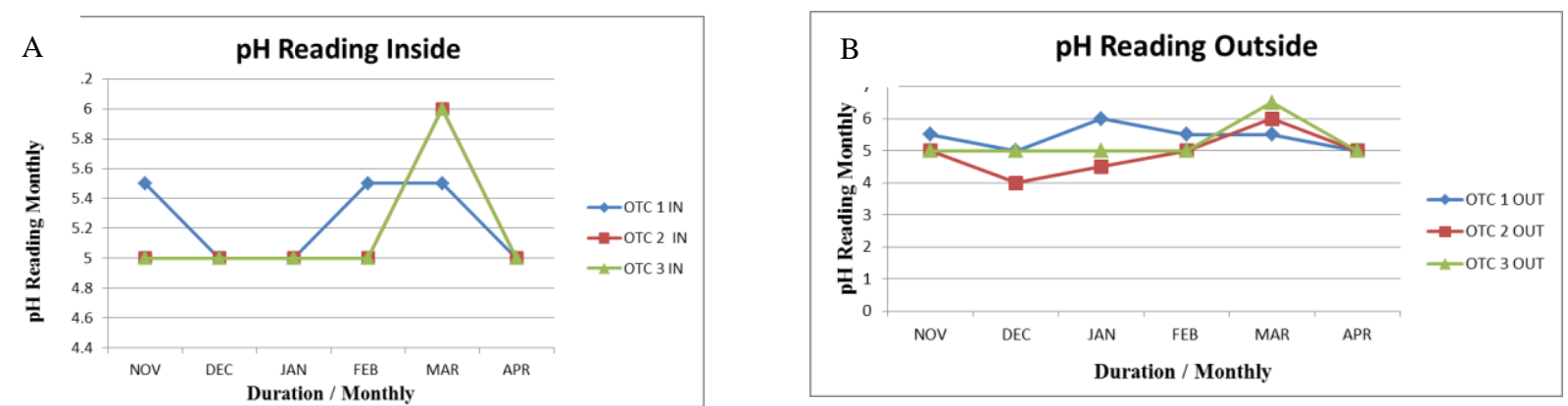

Figure 2: $\mathrm{pH}$ of the soil (A) soil's pH inside the OTC of 3 Different Units from November 2016 to April 2017 and (B) soil's $\mathrm{pH}$ outside the OTC of 3 Different Units from November 2016 to April 2017

\subsection{Total microbial count}

Generally, mix trends were observed in the bacterial count. The results had indicated that the average bacterial count outside the OTC is more than inside OTC for $1 \times 10^{11}$ (24 hours incubation) except for the month of November 2016 and April 2017 (Figure 3). Inversely, the trends had indicated that the average bacterial count inside of the OTC is more than outside of the OTC for $1 \mathrm{X} 10^{11}$ and $10^{12}(48$ hours incubation) except for the month of February 2017 and January 2017 respectively (Figure 3).
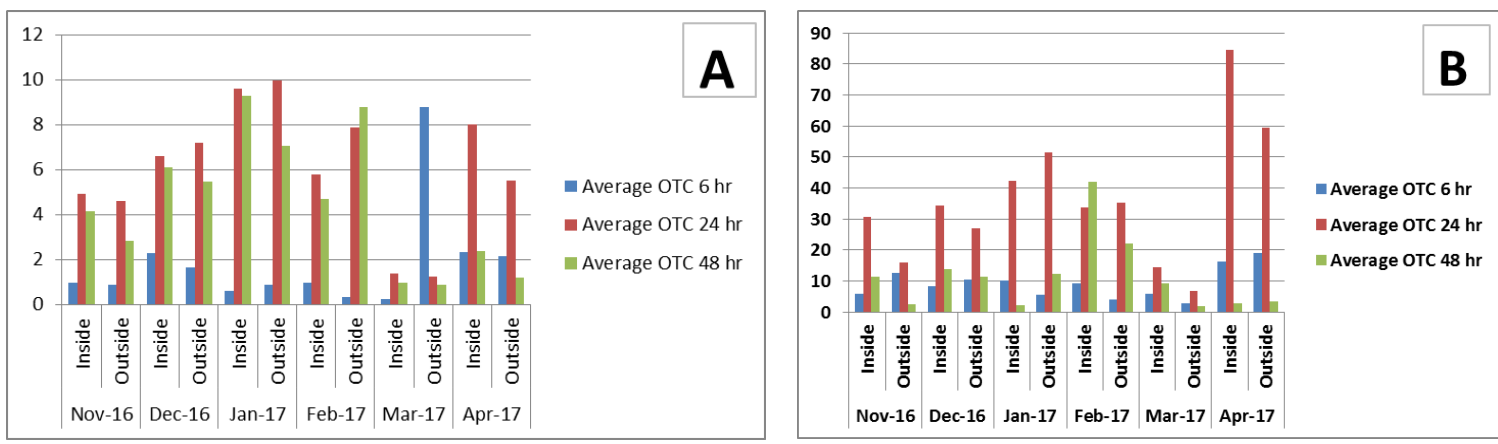

Figure 3: Average of Calculated Colony Forming Unit (A) Calculated of Colony Forming Unit for dilution 1 X $10^{11}$ and (B) Calculated of Colony Forming Unit for dilution 1 X $10^{12}$. All Y-axis refer to Colony Forming Units

\section{Discussion}

In this study, open-top chambers (OTCs) was use to assess as a global warming model for minute climate change studies. Some unwanted effects of the OTC are similar to, but less severe than closed-canopy greenhouses. These unwanted effects are hampering of light, precipitation, wind and heavy rain, in comparison to the control group. The open-top chamber still gives free access to the inside of the chamber for direct light, precipitation, and invertebrates. In the reduction of light, the material of the OTCs is most effective in reducing incoming Photosynthetically Active Radiation (PAR) light (Ashish, et al, 2010)

In the assessment of microbial growth level between inside and outside the OTC and how the heat and the $\mathrm{pH}$ are contributing to it, the result obtained from 3 different OTC had indicated higher in the amount of microbial count outside the OTC. Mix trends were observed in the bacterial count in which the average bacterial count outside the OTC is more than inside for $1 \mathrm{X} 10^{11}$ for fast grower bacteria except for the month of November 2016 and April 2017. Inversely, the trends had indicated that the average bacterial count inside of the OTC is more than outside of the OTC for both dilutions observed in 48 hours incubation except for the month of February 2017 and January 2017 respectively. The OTC effects the distribution of slow grower and fast grower bacteria differently. Further investigation required to ensure which specific group of bacteria sensitive to the minute change due to OTC.

The different time points could be used as a factor related to the microbial growth of the monthly data that was analysed for each OTC. The different trends had been observed on the microbial growth in relation to the duration of incubation time had indicated that there are different types of microbes population inhabited on those soil. There are slow grower (bacteria that appeared more than 24 hours) and fast 
grower bacteria (bacteria that appears overnight) which were cultured from the samples. The effects of the minute change on the temperature, $\mathrm{pH}$ and moist can be some of the factors that had affected the survival of different population of bacteria.

Consequently, upon to their short generation times and rapid turnover, soil bacteria are expected to react speedily to global warming (Pietikainen, Pettersson and Baath, 2005; Rinnan et al., 2007; Zogg et al., 1997). Conversely, Soil fungi, a category of microbes is relatively slow in growth because fungal reactions may lag when compared to bacteria which are a function of substrate accessibility (De Boer et al., 2005). In line with these findings, this study had found that external factors and in addition to the internal factors had contributed significantly to growth of microbes in three soil chambers.

\section{Conclusion}

In conclusion, open-top chambers can be utilised as simple global warming model. OTC might be a suitable tools to unfolds the effects of climatic changes on various microorganism as well as pathogens. The largest OTC can yield temperature increases that correspond with predicted climatic warming. The open-top and the angle of the canopy material making it possible to receive direct light because the light quality and light quantity within the OTC are slightly hampered. The OTC experiment has proven to be effective model in global warming research and therefore, the continuous results obtained would be of great use for further experiments in assessing the effects of global warming on various organism population.

\section{Conflict of Interest}

The authors declare no conflict of interest.

\section{Acknowledgements}

The authors are grateful to Ministry of Science, Technology and Innovation (MOSTI) (Flagship project No. FP0712E012) for the research funding and the Department of Biomedical Science, Faculty of Medicine and Health Sciences, Universiti Putra Malaysia for the facilities.

\subsection{References}

Ashish, K. C., Pratti, P \& Mohan C. N. (2010). Lesser Chamber Effect inside Open Top Chambers Provides Near-Natural Microenvironment for $\mathrm{CO}_{2}$ Enrichment Studies in an Alpine Region of India. Journal of American Science 6(3): 109-117.

Aronson, E. L., \& McNulty, S. G. (2009). Appropriate Experimental Ecosystem Warming Methods By Ecosystem, Objective, And Practicality. Agricultural and Forest Meteorology, 149(11): 1791-1799.

Blankinship, J. C., Niklaus, P. A., \& Hungate, B. A. (2011). A Meta-Analysis Of Responses Of Soil Biota To Global Change. Oecologia, 165(3): 553-565.

Canadell, J. G., Pitelka, L. F., \& Ingram, J. S. (1995). The Effects of Elevated [CO2] On Plant-Soil Carbon Below-Ground: A Summary And Synthesis. Plant and Soil, 187(2): 391-400.

De Boer, W., Folman, L. B., Summerbell, R. C., \& Boddy, L. (2005). Living in a fungal world: impact of fungi on soil bacterialniche development. FEMS Microbiology Review, 29: 795-811.

Fierer, N., McCain, C. M., Meir, P., Zimmermann, M., Rapp, J. M., Silman, M. R., \& Knight, R. (2011). Microbes Do Not Follow The Elevational Diversity Patterns of Plants And Animals. Ecology, 92(4): 797-804.

Högberg, P., Högberg, M., Göttlicher, S., Betson, N., Keel, S., Metcalfe, D., . . L Lundmark, T. (2008). High Temporal Resolution Tracing Of Photosynthate Carbon From The Tree Canopy To Forest Soil Microorganisms. New Phytologist, 177(1): 220-228.

James, J. H. \& Rafiq, I. (2017). Understanding Soil Microbes and Nutrient Recycling. College of Food, Agricultural and Environmental Sciences, https://ohioline.osu.edu/factsheet/SAG-16.

Karhu, K., Fritze, H., Tuomi, M., Vanhala, P., Spetz, P., Kitunen, V., \& Liski, J. (2010). Temperature Sensitivity Of Organic Matter Decomposition In Two Boreal Forest Soil Profiles. Soil Biology and Biochemistry, 42(1): 72-82.

Kennedy, A. C., \& Smith, K. L. (1995). Soil microbial diversity and the sustainability of agricultural soils. In The significance and regulation of soil biodiversity (pp. 75-86). Springer Netherlands.

Macháčová K., (2009). Open top chamber and free air $\mathrm{CO}_{2}$ enrichment - approaches to investigate tree responses to elevated $\mathrm{CO}_{2}$. Italian Society of Silviculture and Forest Ecology, 3: 102-105.

Mangan, S. A., Schnitzer, S. A., Herre, E. A., Mack, K. M., Valencia, M. C., Sanchez, E. I., \& Bever, J. D. (2010). Negative Plant-Soil Feedback Predicts Tree-Species Relative Abundance In A Tropical Forest. Nature, 466(7307): 752-755.

Marion, G., Henry, G., Freckman, D., Johnstone, J., Jones, G., Jones, M., . . Parsons, A. (1997). Open-Top Designs For Manipulating Field Temperature In High-Latitude Ecosystems. Global Change Biology, 3(S1): 20-32.

Melillo, J. M., Butler, S., Johnson, J., Mohan, J., Steudler, P., Lux, H., . . . Scott, L. (2011). Soil Warming, Carbon-Nitrogen Interactions, And Forest Carbon Budgets. Proceedings of the National Academy of Sciences, 108(23): 9508-9512.

Michael J. G., David A. W. \& Marie-Charlotte N (2012). The effect of altered macroclimate on N-fixation by boreal feather mosses. Biology Letters, DOI: $10.1098 / \mathrm{rsbl} .2012 .0429$

Norby, R., Edwards, N., Riggs, J., Abner, C., Wullschledger, S., \& Gunderson, C. (1997). Temperature-Controlled Open-Top Chambers For Global Change Research. Global Change Biology, 3(3), 259-267.

Pettersson, M., \& Bååth, E. (2003). Temperature-Dependent Changes In The Soil Bacterial Community In Limed And Unlimed Soil. FEMS Microbiology Ecology, 45(1), 13-21.

Pietikainen, J. Pettersson, M. \& Baath, E. (2005). Comparison of temperature effects on soil respiration and bacterial and fungal growth rates. Microbiology Ecology, 52(1): 49-58.

Pold, G., \& DeAngelis, K. M. (2013). Up Against The Wall: The Effects Of Climate Warming On Soil Microbial Diversity And The Potential For Feedbacks To The Carbon Cycle. Diversity, 5(2): 409-425.

Ramirez, K. S., Craine, J. M., \& Fierer, N. (2012). Consistent Effects Of Nitrogen Amendments On Soil Microbial Communities And Processes Across Biomes. Global Change Biology, 18(6): 1918-1927.

Rinnan, R., Michelsen, A., Baath, E. \& Jonasson, S. (2007) Fifteen years of climate change manipulations alter soil microbial communities in a subarctic heath ecosystem. Global Change Biology, 13:28-39. 
Sheik, C. S., Beasles, W. H., Mostafa, S. E., Zhou, X., Luo, Y. \& Krumholz, L. R. (2011). Effect of warming and drought on grassland microbial communities. The ISME Journal, 5:1692-1700.

Ulf Molau \& Per Mølgaard (1996) International Tundra Experiment, ITEX Manual $2^{\text {nd }}$ Edition, Danish Polar Center ISBN: 87-90369-04-1

Wu, Z., Dijkstra, P., Koch, G. W., Peñuelas, J., \& Hungate, B. A. (2011). Responses Of Terrestrial Ecosystems To Temperature And Precipitation Change: A Meta-Analysis Of Experimental Manipulation. Global Change Biology, 17(2): 927-942.

$\mathrm{Xu}$, X., Zhou, Y., Ruan, H., Luo, Y. \& Wang J. (2010). Temperature sensitivity increases with soil organic carbon recalcitrance along an elevational gradient in the Wuyi Mountains, China. Soil Biology and Biochemistry, 42(10): 1811-1815.

Zhang, N., Xia, J., Yu, X., Ma, K., \& Wan, S. (2011). Soil Microbial Community Changes And Their Linkages With Ecosystem Carbon Exchange Under Asymmetrically Diurnal Warming. Soil Biology and Biochemistry, 43(10): 2053-2059.

Zhang, Y., Dong, S., Gao, Q., Liu, S., Ganjurjav, H., Wang, X., .. Wu, X. (2017). Soil Bacterial And Fungal Diversity Differently Correlated With Soil Biochemistry In Alpine Grassland Ecosystems In Response To Environmental Changes. Scientific Reports, 7.

Zhao, C., Zhu, L., Liang, J., Yin, H., Yin, C., Li, D., . . Liu, Q. (2014). Effects Of Experimental Warming And Nitrogen Fertilization On Soil Microbial Communities And Processes Of Two Subalpine Coniferous Species In Eastern Tibetan Plateau, China. Plant and Soil, 382(1): 189-201. doi:10.1007/s11104-014-2153-2

Zogg, G. P., Zak, D. R., Ringelberg, D. B., White, D. C., MacDonald, N. W., \& Pregitzer, K. S. (1997). Compositional And Functional Shifts In Microbial Communities Due To Soil Warming. Soil Science Society of America Journal, 61(2): 475-481. 